\title{
Extent of awareness regarding periodontal disease in patients of diabetes mellitus
}

\author{
Anuradha Arun Khakre1, Anup Shelke², Vijaykumar Girhe ${ }^{3}$, Kshama Chandurkar ${ }^{4}$, Rohit Kulshrestha ${ }^{5, *}$, Vinay \\ Umale $^{6}$
}

${ }^{1}$ PG Student, ${ }^{2,3}$ Reader, ${ }^{4-6}$ Senior Lecturer, ${ }^{1,2}$ Dept. of Periodontology, ${ }^{3}$ Dept. of Oral \& Maxillofacial Surgery, ${ }^{4}$ Dept. of Oral Pathology, ${ }^{5,6}$ Dept. of Orthodontics, ${ }^{1-3}$ Dr. H.S.R.S.M's Dental College and Hospital, Hingoli, Maharashtra, ${ }^{4,6}$ Yogita Dental College and Hospital, Khed, Maharashtra, ${ }^{5}$ Terna Dental College and Hospital, Navi Mumbai, Maharashtra, India

*Corresponding Author: Rohit Kulshrestha

Email: kulrohit@gmail.com

\begin{abstract}
Introduction: Diabetes mellitus (DM) being a common metabolic disorder constitutes a global public health burden. As evidence from clinical research showing a strong relationship between DM \& periodontal disease is mounting, this necessitates the global awareness about this relationship.

Aim: Aim of the study is to assess the level of awareness about the mutual relationship between DM \& periodontitis among high risk age group of the diabetic patients.

Materials and Methods: A structured, closed ended questionnaire either in English or in local language were distributed and collected from 302 diabetic patients who are willing to participate in the study. The clinical implication of our study is to check the awareness of relationship between DM and periodontitis in these patients \& recommend diabetic patients to see the dentist regularly.

Results: Majority of patients $(83.4 \%)$ of patient were not advised by their treating physician about regular dental checkup after being diagnosed as having Diabetes. After recording OHIS index it was observed that $44.2 \%$ of the population was unaware about the severity of disease.

Conclusion: There is an insufficient knowledge among diabetes mellitus individuals about the mutual relationship between diabetes and periodontitis. To promote proper oral health and to reduce the risk of oral diseases, health professionals in both the dental and medical fields need to take responsibility for educating the public about the oral manifestations of diabetes and its complications.
\end{abstract}

Keywords: Diabetes mellitus, hyperglycemia, Bidirectional relation, Awareness.

\section{Introduction}

Periodontitis is one of the common local inflammatory diseases of tooth supporting tissue. It is initiated by microorganisms present in dental plaque and is characterized by loss of the connective tissue and alveolar bone surrounding the teeth. Accumulation of bacterial biofilm on tooth surfaces initially results in inflammation of the gingival soft tissues known as gingivitis, although under normal physiological conditions improvement in oral hygiene will result in complete resolution of the inflammation ${ }^{1}$ Association between various systemic diseases and periodontitis has been established and is the focus of most researches in the recent past among all; diabetes mellitus is the common prevalent systemic disease and has been proved to have a bidirectional relationship with periodontitis. ${ }^{2}$

Diabetes mellitus is a metabolic disorder characterized by hyperglycemia due to defective secretion or activity of insulin. ${ }^{3}$ It may be further complicated by poor regulation of protein and lipid metabolism. Chronic hyperglycemia is associated with long-term dysfunction and damage to numerous end-organs, with marked effects on the eyes, kidneys, heart, nerves, and blood vessels ${ }^{4}$. Although periodontitis is a recognized complication of diabetes, people with well-controlled diabetes, having good oral hygiene, are not at an increased risk of periodontitis. However, their susceptibility to periodontitis is significantly increased when their diabetes is poorly controlled, particularly in smokers.

General practitioners and health-care providers for diabetic patients should also possess basic dental knowledge to find out the signs and symptoms of dental diseases to provide appropriate treatment or advice to visit a dentist. Hence, the present study aimed to assess the levels of awareness about the relationship between diabetes mellitus and periodontitis among high-risk age group of the general population. In addition, the attitude of general physicians in suggesting the diabetic patients to visit a dentist has also been assessed.

\section{Materials and Methods}

A structured, closed-ended questionnaire was prepared in English and in the local language (Marathi) for evaluating the main aim of the study. The study was designed and conducted at the diabetic centers in Amravati district and Hingoli district urban areas. The questionnaire was distributed among patients attending diabetic center and satisfying the following selection criteria: Patients of age 25-55 years; patients without any condition that limits their ability to brush their teeth; patients with not $<20$ teeth; and patients who can read and write either in English or in the local language (Marathi).

Patients who readily agreed to participate in the study were provided with the self-constructed questionnaire. Prior to study, a questionnaire was pretested and validated for construct and content validity, reliability, and ease of use. Content and construct validity shows no significant changes. Demographic data such as age, sex, educational status, and occupation have been recorded and documented. A total of 302 participants were included in the study and the completed questionnaire forms from the participants were 
collected and analyzed. The statistical software namely SPSS version 20.0 was used to calculate descriptive data and to perform Chi square test and Spearman correlation test for the analysis of data for assessing the association between diabetic population and knowledge about the mutual relationship.

\section{Results}

Out of the 302 patients questioned, 173 were male and 129 were female (Table 1). Educational, Occupational, Family income per month and Socio-economic status were recorded using Modified Kuppuswamy scale-2017.

Out of 302 patients $37(12.3 \%)$ were Profession or Honors holders, $122(40.4 \%)$ were Graduate or Post graduate, $77(25.5 \%)$ had Intermediate or post high school diploma, $30(9.9 \%)$ were high school certified and $12(4 \%)$ were intermediate or post high school certified, while 18 $(2.00 \%)$ were illiterate (Table 2 ).

Among study sample, majority $(79,26.2 \%)$ were Semiprofessional while 73 (24.2\%) were from Clerks, Shop keepers or Farmers. Nearly 54 out of $302(17.9 \%)$ were Professional, $36(11.9 \%)$ were Skilled and Semi-skilled workers while $6(2 \%)$ were unemployed (Table 3$)$.

Majority $(121,40.1 \%)$ of patients had monthly family income between 10357 and 15535 while $72(23.8 \%)$ had family income per month in the range of 15536-20714. Nearly $49(16.2 \%)$ had family income per month in the range of 20715-41429 and 42 out of 302 (13.9\%) fell into the range of 6214-10356. 12 (4\%) had family income per month between 2092- 6213 while $6(2 \%)$ had less than 2091 (Table 4).

As per Modified Kuppuswamy scale 2017, Majority of patient 157 (51.9\%) fell into Upper lower class while 53 (17.5\%), 18 (5.9\%), 7 (2.3\%) were in Lower Middle, Upper middle and Upper class respectively (Table 5).

Among the study sample, majority $(187,61.9 \%)$ of diabetic patient had Diabetes for more than 5 years.

Majority of patients $(140,46.4 \%)$ acknowledged the relation between brushing habits and gums disease while 78 (25.8\%) disagreed about any relationship between the two. About 84 out of $302(27.8 \%)$ were unaware about any relationship. (Table 6)

Majority of patients $173(57.2 \%)$ were regular (6-9 monthly) for their dental checkup while 129 (42.7\%) were irregular for the same (Graph 2).

Out of 302 patients, majority of patients $(232,76.8 \%)$ believed that their gum status was healthy while $70(23.1 \%)$ believed that their gum status was unhealthy. Those patients who acknowledged the diseased status of their gum were further asked about the perceived severity of their gums disease. Majority of patents $(31,44.2 \%)$ were unaware of the severity of their gums disease while 22 out of 70 $(31.4 \%)$ believed it to be mild, $10(14.4 \%)$ believed it to be moderate and $7(10 \%)$ believed it to be severe (Table 7).

To confirm their oral hygiene, Oral Hygiene Index Simplified (OHIS index) was recorded for all 302 patients.
Out of those $40(13.2 \%)$ were found to have good oral hygiene, $112(37 \%)$ had fair oral hygiene while $150(49.6 \%)$ were found to have poor oral hygiene (Table 8). This highlights the disparity between the actual status and the perceived status of oral hygiene among the study population.

The relationship between Educational, Occupational, Income status, Socio economic Status (SES) and Oral hygiene (OHIS Status) was also assessed by calculating Pearson Correlation (Table 9). It showed downhill (negative) linear relationship between Educational status, Occupational status, Socio-economic status and Oral hygiene (OHIS Status). It highlights the possibility that the oral hygiene improves with higher Educational, Occupational, Income status.

When patients were asked about their perception about relationship between Diabetes and gum health. Majority of the patients 147 (48\%) were unaware of any relationship between Diabetes and Periodontal diseases while only 61 out of $302(20.2 \%)$ acknowledged the relation between Diabetes and Periodontitis. 94 (31.1\%) opted for 'No' relationship between Diabetes and Periodontal diseases (Table 10).

When those who acknowledged the relation between Diabetes and Periodontitis were further enquired about their source of information: 22 out of $61(36.06 \%)$ reported it to be newspaper, 15 (24.5\%) reported television. 18 (29.50\%) got the information from friends while $6(9.8 \%)$ were counseled by their doctor (Graph 5). It points out the probability of either lack of awareness among healthcare professionals or disregardful attitude.

When the participants were asked about their perception about effect of poor oral hygiene on increased risk of Diabetes. Majority of the patients $169(56 \%)$ were unaware of any effect of poor oral hygiene on Diabetes while only 54 out of 302 (17.9\%) acknowledged the negative effect of poor oral hygiene in Diabetes. 79 (26.2\%) opted for 'No' relationship between and poor oral hygiene and Diabetes (Table 11).

When further enquired about protective role of maintenance of good oral hygiene in Diabetes: Majority of the patients $182(60.3 \%)$ were unaware of protective role of maintenance of good oral hygiene in Diabetes while only 52 out of $302(17.2 \%)$ acknowledged the positive effect of good oral hygiene in Diabetes. 68 (22.5\%) opted for 'No' relationship between and good oral hygiene and Diabetes (Table 12).

Majority of patients (83.4\%) of patient agreed that they were not advised by their treating physician about regular dental checkup after being diagnosed as having Diabetes (Graph 6). 
Graph 1: Response to Question 3: Do you think there is any relation between your brushing habit and present gum status?

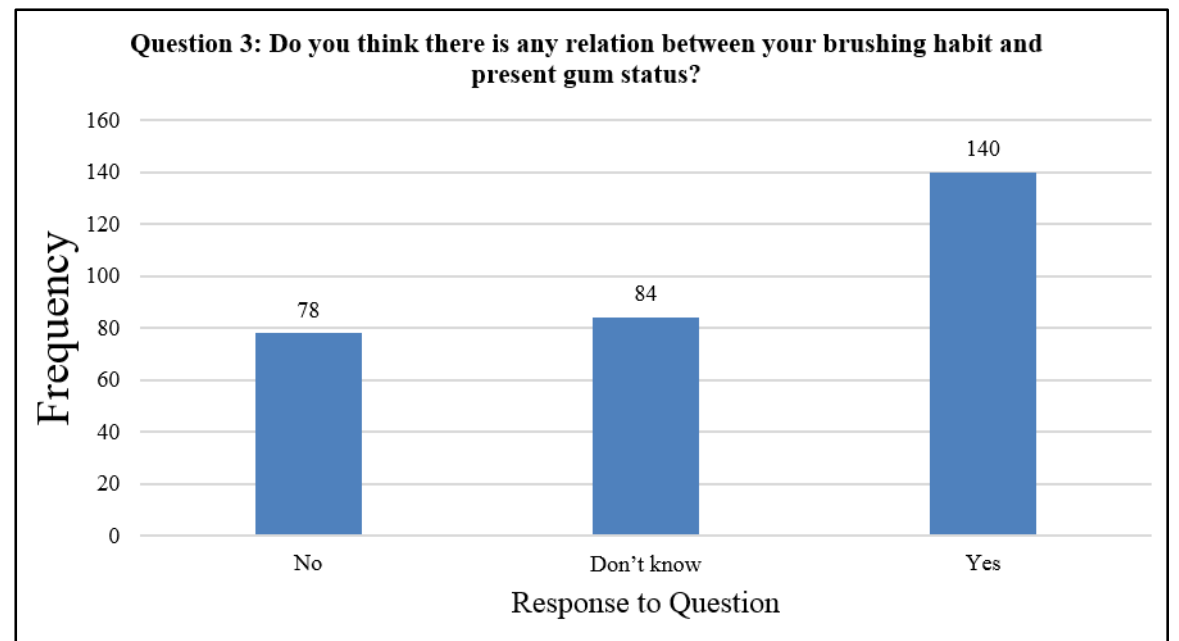

Graph 2: Response to Question 4: Do you get your checkup done regularly?

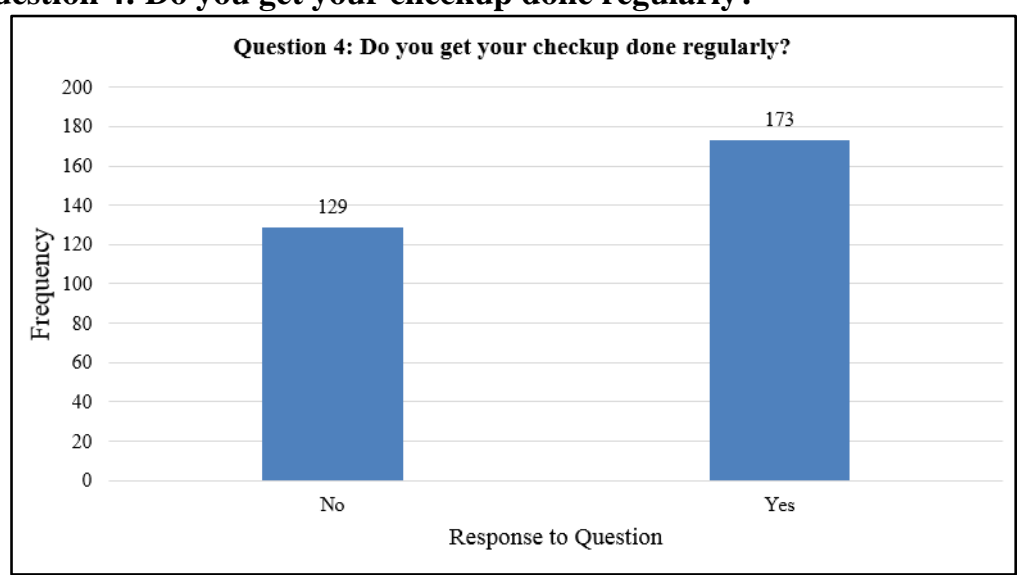

Graph 3: Response to Question 6: In your opinion what is your present gum status?

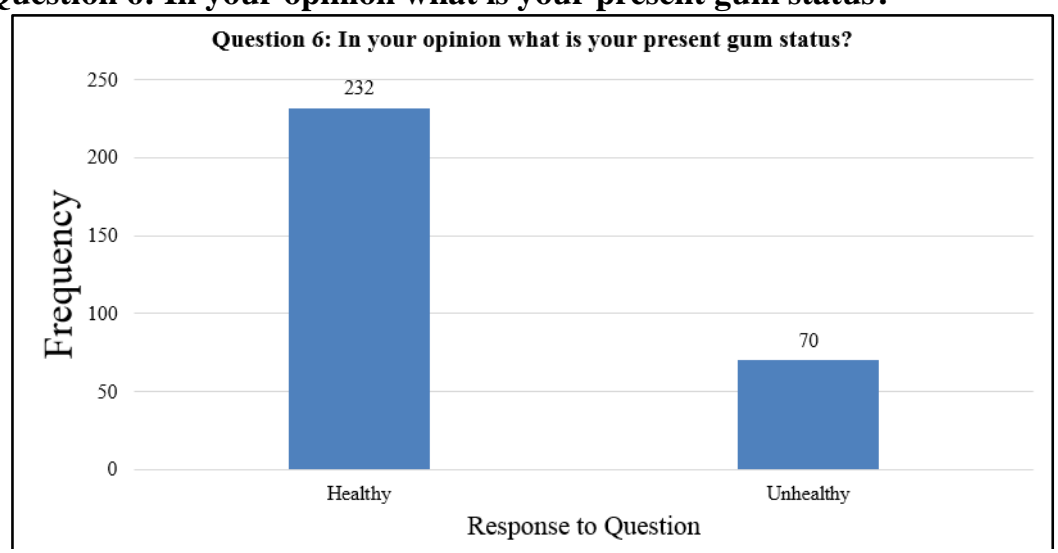


Graph 4: Oral Hygiene Index Simplified (OHIS index) Vs Perceived Gum Status

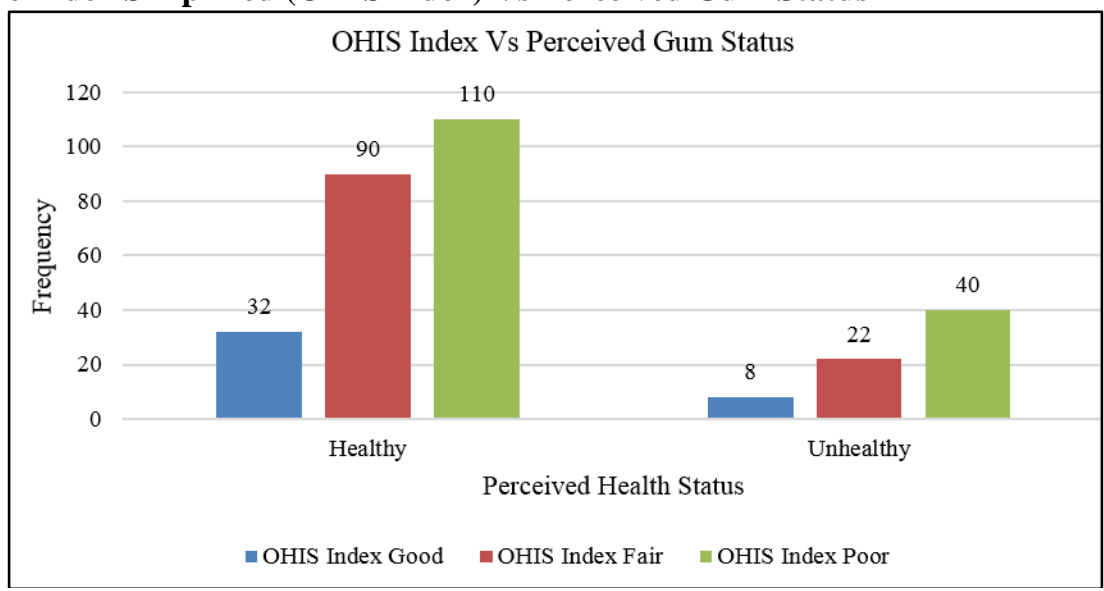

Graph 5: Source of information 1)News paper 2)Television 3)Friends 4)Doctor

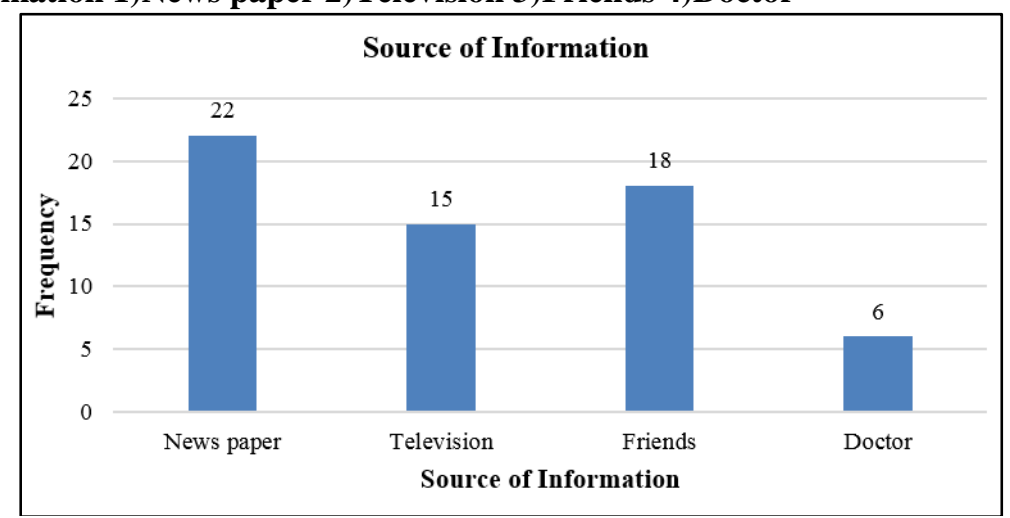

Graph 6: Has your diabeteologist ever advised you to consult a dentist?

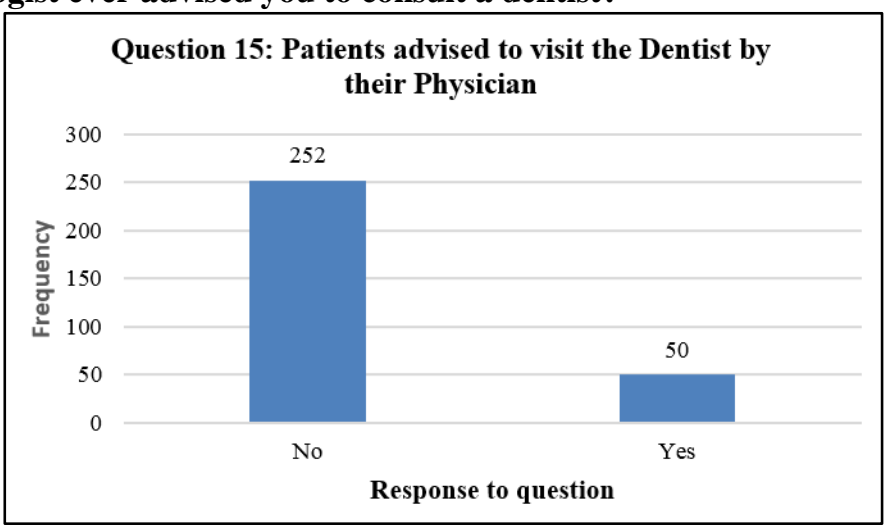

Table 1: Gender wise distribution of patients

\begin{tabular}{|l|c|c|c|}
\hline \multicolumn{2}{|c|}{} & Frequency $(\mathbf{n}=\mathbf{3 0 2})$ & Percent \\
\hline \multirow{2}{*}{ Gender } & Male & 173 & 57.3 \\
\cline { 2 - 4 } & Female & 129 & 42.7 \\
\hline
\end{tabular}

Table 2: Educational Status

\begin{tabular}{|c|c|c|c|}
\hline S. No & Educational Status & Frequency $(\mathbf{n}=\mathbf{3 0 2})$ & Percentage \\
\hline 1 & Profession or Honours & 37 & 12.3 \\
\hline 2 & Graduate or Post graduate & 122 & 40.4 \\
\hline 3 & Intermediate or post high school diploma & 77 & 25.5 \\
\hline 4 & High school certificate & 30 & 9.9 \\
\hline
\end{tabular}




\begin{tabular}{|l|c|c|c|}
\hline 5 & Middle school certificate & 12 & 4.0 \\
\hline 6 & Primary school certificate & 6 & 2.0 \\
\hline 7 & Illiterate & 18 & 6.0 \\
\hline \multicolumn{2}{|c|}{ Total } & 302 & 100.0 \\
\hline
\end{tabular}

Table 3: Occupational status

\begin{tabular}{|l|c|c|c|}
\hline S. No & Occupational Status & Frequency $(\mathbf{n}=\mathbf{3 0 2})$ & Percentage \\
\hline 1 & Professional & 54 & 17.9 \\
\hline 2 & Semi Professional & 79 & 26.2 \\
\hline 3 & Clerical, Shop owner, Farmer & 73 & 24.2 \\
\hline 4 & Skilled worker & 36 & 11.9 \\
\hline 5 & Semi-Skilled worker & 36 & 11.9 \\
\hline 6 & Unskilled worker & 18 & 6.0 \\
\hline 7 & Unemployed & 6 & 2.0 \\
\hline Total & & 302 & 100.0 \\
\hline
\end{tabular}

Table 4: Family income in Rs per month

\begin{tabular}{|l|c|c|c|}
\hline S. No & Family income in Rs per month & Frequency $(\mathbf{n = 3 0 2})$ & Percentage \\
\hline 1 & $>41430$ & 00 & 00 \\
\hline 2 & $20715-41429$ & 49 & 16.2 \\
\hline 3 & $15536-20714$ & 72 & 23.8 \\
\hline 4 & $10357-15535$ & 121 & 40.1 \\
\hline 5 & $6214-10356$ & 42 & 13.9 \\
\hline 6 & $2092-6213$ & 12 & 4.0 \\
\hline 7 & $<2091$ & 6 & 2.0 \\
\hline Total & & 302 & 100.0 \\
\hline
\end{tabular}

Table 5: Socio- economic Status

\begin{tabular}{|l|c|c|c|}
\hline S. No & Socio-economic Status & Frequency $(\mathbf{n = 3 0 2})$ & Percentage \\
\hline 1 & Lower & 67 & 22.1 \\
\hline 2 & Upper Lower & 157 & 51.9 \\
\hline 3 & Lower Middle & 53 & 17.5 \\
\hline 4 & Upper Middle & 18 & 5.9 \\
\hline 5 & Upper & 7 & 2.3 \\
\hline \multicolumn{2}{|c|}{ Total } & 302 & 100.0 \\
\hline
\end{tabular}

Table 6: Response to Question 3: Do you think there is any relation between your brushing habit and present gum status?

\begin{tabular}{|c|c|c|c|}
\hline Question & Response & Frequency (n=302) & Percentage \\
\hline \multirow{2}{*}{$\begin{array}{l}\text { Q3. Do you think there is any relation between } \\
\text { your brushing habit and present gum status? }\end{array}$} & No & 78 & 25.8 \\
\cline { 2 - 4 } & Don't know & 84 & 27.8 \\
\cline { 2 - 4 } & Yes & 140 & 46.4 \\
\hline \multicolumn{2}{|c|}{ Total } & 302 & 100.0 \\
\hline
\end{tabular}

Table 7: Response to Question 6: In your opinion what is your present gum status?

\begin{tabular}{|l|c|c|c|}
\hline Question & Response & Frequency $(\mathbf{n = 3 0 2})$ & Percentage \\
\hline $\begin{array}{l}\text { Q6. In your opinion what is your present gum } \\
\text { status? }\end{array}$ & Healthy & 232 & 76.8 \\
\hline & Unhealthy & 70 & 23.1 \\
\hline \multicolumn{2}{|c|}{ Total } & 302 & 100.0 \\
\hline
\end{tabular}

Table 8: Oral Hygiene Index Simplified (OHIS index) Vs Perceived Gum Status

\begin{tabular}{|l|c|c|c|c|}
\hline \multirow{2}{*}{ Perceived Gum Status } & \multicolumn{3}{|c|}{ OHIS Index } & \multirow{2}{*}{ Total } \\
\cline { 2 - 4 } & Good & Fair & Poor & \\
\hline Healthy & 32 & 90 & 110 & 232 \\
\hline Unhealthy & 8 & 22 & 40 & 70 \\
\hline Total & 40 & 112 & 150 & 302 \\
\hline
\end{tabular}


Table 9: Relationship between Educational, Occupational, Income status, Socio economic status and oral hygiene

\begin{tabular}{|l|c|c|}
\hline \multicolumn{2}{|c|}{} & OHIS Status \\
\hline \multirow{2}{*}{ Educational Status } & Pearson Correlation & -.010 \\
\cline { 2 - 3 } & Sig. (2-tailed) & .043 \\
\hline \multirow{2}{*}{ Occupational Status } & Pearson Correlation & -.014 \\
\cline { 2 - 3 } & Sig. (2-tailed) & .840 \\
\hline \multirow{2}{*}{ Socio-Ecome Status } & Pearson Correlation & .034 \\
\cline { 2 - 3 } & Sig. (2-tailed) & .032 \\
\hline
\end{tabular}

Table 10: Response to Question 11: Do you think is there any relation between diabetes and gum health?

\begin{tabular}{|l|c|c|c|}
\hline Question & Response & Frequency (n=302) & Percentage \\
\hline \multirow{2}{*}{$\begin{array}{l}\text { Q11. Do you think is there any relation between } \\
\text { diabetes and gum health? }\end{array}$} & No & 94 & 31.1 \\
\cline { 2 - 4 } & Don't know & 147 & 48.7 \\
\cline { 2 - 4 } & Yes & 61 & 20.2 \\
\hline \multicolumn{2}{|c}{ Total } & 302 & 100.0 \\
\hline
\end{tabular}

Table 11: Response to Question 13: Do you think is there any relation between diabetes and gum health?

\begin{tabular}{|l|c|c|c|}
\hline Question & Response & $\begin{array}{c}\text { Frequency } \\
(\mathbf{n = 3 0 2})\end{array}$ & Percentage \\
\hline $\begin{array}{l}\text { Q13. Are you aware about poor oral health } \\
\text { increases your risk of diabetes? }\end{array}$ & No & 79 & 26.2 \\
\cline { 2 - 4 } & Don't know & 169 & 56.0 \\
\cline { 2 - 4 } & Yes & 54 & 17.9 \\
\hline \multicolumn{2}{|c}{ Total } & 302 & 100.0 \\
\hline
\end{tabular}

Table 12: Do you know that good oral hygiene maintenance might help to protect you from diabetes?

\begin{tabular}{|c|c|c|c|}
\hline Question & Response & Frequency $(n=302)$ & Percentage \\
\hline \multirow{3}{*}{$\begin{array}{l}\text { Q14. Do you know that good oral hygiene } \\
\text { maintenance might help to protect you from } \\
\text { diabetes? }\end{array}$} & No & 68 & 22.6 \\
\hline & Don't know & 182 & 56.0 \\
\hline & Yes & 52 & 17.2 \\
\hline \multicolumn{2}{|l|}{ Total } & 302 & 100.0 \\
\hline
\end{tabular}

\section{Discussion}

Both Periodontitis and Diabetes mellitus are commonly occurring chronic diseases and generate enormous costs for the public health-care system. Numerous studies, review articles $^{5,6}$ and meta-analyses ${ }^{7}$ indicated a mutual influence between Periodontitis and Diabetes mellitus. The study conducted by Mealey and Oates in 2006 reported the prevalence of Periodontitis in patients of Diabetes mellitus to be double or even triple as compare to that of normal population ${ }^{5}$ Similar results were found in study conducted by Taylor et $\mathrm{al}^{8}$ and Emrich et $\mathrm{al}^{9}$ in which they found that Periodontal disease were 2.8 times more likely and Alveolar bone loss progression was 4.2 times more likely in patients with Diabetes mellitus.

Several factors have been postulated that prevent patients with Diabetes mellitus from seeking dental care viz lack knowledge about the need for dental check-up, economic condition, the fear of dental treatment, misconceptions and educational status of patient. Though this bidirectional relationship between Periodontitis and Diabetes mellitus is well understood, the awareness in general population is still lacking. Current study was undertaken to estimate the extent of awareness about the Periodontitis in patients of Diabetes mellitus and possible influence of above mentioned factors by questionnaire method.

In the present study, the majority of patients were graduate, semiprofessional and had monthly family income between 10357-15535 Rs and belonged to upper lower class (Table 2-5). Majority of patients were suffering from Diabetes mellitus for more than 5 years and were aware of importance of regular brushing habits in maintaining healthy gums. In a study sample, $57.2 \%$ of the patients were regular for their dental checkup. However, in a study by Aggarwal and Panat ${ }^{10}$ only $10.8 \%$ of the patients with Diabetes mellitus were found to be regular for their dental check-ups and suboptimal oral hygiene behaviour. The difference might be because of higher socio-economic status of study sample. Even though, around $2 / 3^{\text {rd }}$ of patients thought their gum status being healthy, only $13 \%$ had good oral hygiene when checked with OHIS index. 
When the relationship between Educational, Occupational, Income status, Socio economic Status (SES) and Oral hygiene (OHIS Status) was assessed, Gum status was found to improve with higher Educational, Occupational, Income status, Socio economic Status (SES). Similar findings were also found in study done by Taiwo $\mathrm{JO}^{11}$ in which they found the influence of educational status was highly significant on the frequency of tooth-brushing and ultimately on oral hygiene. According to Sukhvinder Singh Oberoi et al, ${ }^{12}$ the oral hygiene practices of the patients from upper and lower middle class was found to be satisfactory whereas it was poor among patients belonging to lower and upper lower class.

In a study sample only $20 \%$ of the study population was aware of relationship between Diabetes and poor gum health which correlates with findings of study done by Weinspach et al in which less than 50\% population was aware about the bidirectional relationship. ${ }^{13}$ More than half of the study population was found to be unaware of protective role of maintenance of good oral hygiene in Diabetes. Similar findings were found in a study by $\mathrm{Al}$ Habashneh $\mathrm{R}^{14}$ in a Jordian population in which they concluded that knowledge about diabetes and periodontal health among diabetic patients is low, and majority of patients were unaware of the oral health complications of their disease and the need for proper preventive care.

In a study sample, less than $10 \%$ were counseled by their doctor regarding the bidirectional relationship between Diabetes mellitus and Periodontitis and around $83 \%$ of population reported of not being advised by their treating physician about regular dental checkup after being diagnosed as having Diabetes mellitus. It points out the probability of either lack of awareness among healthcare professionals or disregardful attitude. Lin et al ${ }^{15}$ also stated that endocrinologists and dentists are not equally equipped with the knowledge about the relationship between Diabetes mellitus and periodontitis. Eldarrat et $\mathrm{al}^{16}$ also concurred with the need to develop programs to educate the public about the oral manifestations of diabetes and its complications for oral health by health professionals in both the dental and medical fields to promote proper oral health and to reduce the risk of oral diseases.

\section{Conclusion}

This study highlights the lack of awareness about bi directional relationship between diabetes and periodontitis among the diabetics and possible disgraceful attitude among health care professional. It also highlights the disparity among perceived and actual oral health status among high risk population. This study brings into focus the need of proper counseling by health care professional among high risk population about maintaining proper oral hygiene and regular dental checkup.
2. Chávarry NG, Vettore MV, Sansone C, Sheiham A. The relationship between diabetes mellitus and destructive periodontal disease: A meta-analysis. Oral Health Prev Dent 2009;7:107-127.

3. Tan M, Daneman D, Lau D, others a. Diabetes in Canada: strategies towards 2000. Toronto; 1997.

4. Mealey BL, Moritz AJ. Hormonal influences: Effects of diabetes mellitus and endogenous female sex steroid hormones on the periodontium. Periodontol. 2003;32:59-81.

5. Mealey BL, Oates TW; American Academy of Periodontology. Diabetes mellitus and periodontal diseases. J Periodontol 2006;77:1289-303.

6. Casanova L, Hughes FJ, Preshaw PM. Diabetes and periodontal disease: A two-way relationship. Br Dent J 2014;217:433-437.

7. Chávarry NG, Vettore MV, Sansone C, Sheiham A. The relationship between diabetes mellitus and destructive periodontal disease: A meta-analysis. Oral Health Prev Dent 2009;7:107-127.

8. Taylor GW. Bidirectional interrelationships between diabetes and periodontal diseases: An epidemiologic perspective. Ann Periodontol 2001;6:99-112.

9. Emrich LJ, Shlossman M, Genco RJ. Periodontal disease in non-insulin-dependent diabetes mellitus. J Periodontol 1991;62:123-131.

10. Aggarwal A, Panat SR. Oral health behavior and HbA1c in Indian adults with type 2 diabetes. J Oral Sci 2012;54:293301.

11. Taiwo JO. Oral health education needs of diabetic patients in Ibadan. Afr J Med Med Sci. 2000 Sep-Dec;29(3-4):269-274.

12. Sukhvinder Singh Oberoi, Gaurav Sharma, Avneet Oberoi. A cross sectional survey to assess the effect of socioeconomic status on the oral hygiene habits. J Indian Soc Periodontol 2016;20(5).

13. Weinspach K, Staufenbiel I, Memenga-Nicksch S, Ernst S, Geurtsen W, Günay H. Level of information about the relationship between diabetes mellitus and periodontitis Results from a nationwide diabetes information program. Eur $J$ Med Res 2013;18:6.

14. Al Habashneh R, Khader Y, Hammad MM, Almuradi M. Knowledge and awareness about diabetes and periodontal health among Jordanians. J Diabetes Complications. 2010;24(6):409-414. doi: 10.1016/j.jdiacomp.2009.06.001.

15. Lin H, Zhang H, Yan Y, Liu D, Zhang R, Liu Y. Knowledge, awareness, and behaviors of endocrinologists and dentists for the relationship between diabetes and periodontitis. Diabetes Res Clin Pract 2014;106:428-434.

16. Eldarrat, Aziza H. Awareness and Attitude of Diabetic Patients about Their Increased Risk for Oral Diseases. Oral Health Prev Dent 2011;9(3):235-241.

How to cite this article: Khakre AA, Shelke A, Girhe V, Chandurkar K, Kulshrestha R, Umale V. Extent of awareness regarding periodontal disease in patients of diabetes mellitus. Int Dent J Student's Res. 2018;6(4): 85-91.

\section{References}

1. Löe H, Theilade E, Jensen SB. Experimental gingivitis in man. J Periodontol 1965;36:177-187. 